\title{
Electrostatic vs. Inductive Effects in Phosphine Ligand Donor Properties, Reactivity, and Catalysis
}

\author{
Margaret L. Kelty, ${ }^{\ddagger}$ Andrew J. McNeece, ${ }^{\ddagger}$ Alexander S. Filatov and John S. Anderson*[a]
}

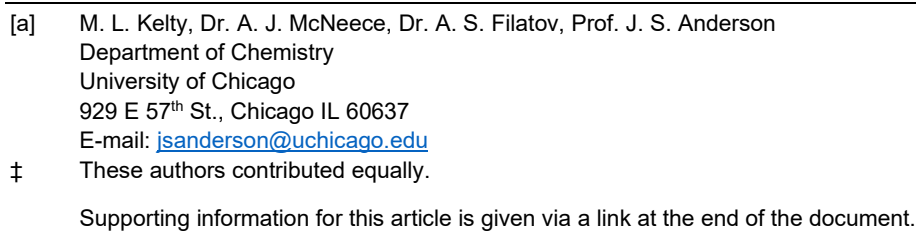

\begin{abstract}
The use of charged groups to leverage electrostatics in molecular systems is a promising strategy to tune reactivity. However disentangling the relative influences of inductive (through-bond) and electrostatic (through-space) contributions from charged groups is a long-standing challenge. To quantify the interplay of these effects we have synthesized and analyzed the anionic phosphine, $\mathrm{Ph}_{2} \mathrm{PCH}_{2} \mathrm{BF}_{3}{ }^{-}$, its selenide, and its transition metal complexes. Solvent-dependent changes in donor strength consistent with Coulomb's law support a dominant electrostatic contribution to donor strength, while computations highlight the impact of charge position and orientation. Finally, inclusion of the anion also greatly accelerates $\mathrm{C}-\mathrm{F}$ oxidative addition reactivity in $\mathrm{Ni}$ complexes, allowing for rapid catalytic $\mathrm{C}-\mathrm{F}$ borylation of fluoroarenes. These results show that covalently bound charged functionalities can exert a major electrostatic influence under common solution phase reaction conditions.
\end{abstract}

\section{Introduction}

Spectroscopic and computational studies have cited oriented electric fields in active sites as key contributors to enzymatic reactivity. ${ }^{[1-7]}$ Enzymes maintain and orient electric fields using polar and charged functional groups in the protein scaffold around the active site, a strategy that is appealing for synthetic molecular systems but difficult to mimic. ${ }^{[8-12]}$ Multiple approaches have been proposed for incorporating similar electric fields into systems that lack an enzymatic superstructure. Electric fields can be directly applied to synthetic compounds through attachment to electrode surfaces or STM tips and these approaches have been shown to increase catalytic rates. ${ }^{[13-23]}$ Another approach is to rationally append charged functional groups onto molecular scaffolds to offer control over the orientation and magnitude of electrostatic effects. Indeed, there has been enormous interest in modeling or leveraging electrostatic interactions in organic and inorganic molecules. ${ }^{[24-45]}$ Computations have shown that these factors can have a large impact on reactivity and catalysis, ${ }^{[46-59]}$ such as accelerating coupling reactions through the lowering of barriers to oxidative addition. ${ }^{[60]}$

A detailed understanding of the relative importance of inductive or electrostatic effects would be valuable in tuning molecular reactivity. However, experimentally parsing out the relative inductive and electrostatic contributions to reactivity and electronic structure from charged functional groups is challenging even in simple systems. A prime example of this is in classic Hammett literature where inductive through-bond and electrostatic through-space influences from substituents were predominantly treated as one lump effect, sometimes referred to as $\sigma_{\mathrm{i}}{ }^{[61]}$ However, in a subset of this literature, there has been considerable debate on whether electrostatics or through-bond electron density factors are dominant in $\sigma_{i}$. Hammett originally considered the influence of substituents to be entirely electrostatic in nature, a view supported by Ri, Eyring, and Westheimer. ${ }^{[62,63]}$ Conversely, Jaffe considered substituent effects primarily through electron density, foreshadowing modern computational analyses. ${ }^{[64,65]}$ The efficacy of both methods in rationalizing reactivity trends supports that both electrostatic and inductive contributions are active, and methods to distinguish between these contributions are still being pursued to this day. ${ }^{[66]}$ Obtaining a more detailed understanding of the relative magnitude of inductive and electrostatic factors would be valuable, particularly as leveraging through-space interactions should serve as an ideal strategy to break free-energy relationships. ${ }^{[67-73]}$

Phosphines are ideal scaffolds to quantify the influence of electrostatics as these ligands feature prominently in catalysis and have well defined parameters for their donor strength such as the Tolman Electronic Parameter (TEP) ${ }^{[74]}$ Indeed, cationic and anionic functional groups have previously been incorporated into phosphines, frequently leading to distinct properties or reactivity in comparison to neutral analogues. ${ }^{[1,75-88]}$ Still, how charged residues change phosphine properties, namely the relative contributions of through-space or through-bond effects, has not been investigated. This gap is noteworthy as a recent computational study into the impact of electric fields on the reactivity of a $\mathrm{PMe}_{3}$ supported $\mathrm{Pd}$ complex suggests that anions can accelerate oxidative addition through the application of a local electric field even without covalent bonding interactions. ${ }^{[60]}$ In order to parse out these contributions, we sought to prepare a simple anionic phosphine scaffold in which a single compact anionic functional group is appended to a phosphine through an

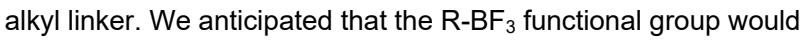
provide a more compact charge in comparison to commonly used phenyl borates, which electrostatic potential maps suggest have a more diffuse charge. ${ }^{[79]}$ Additionally, alkyl linkers should

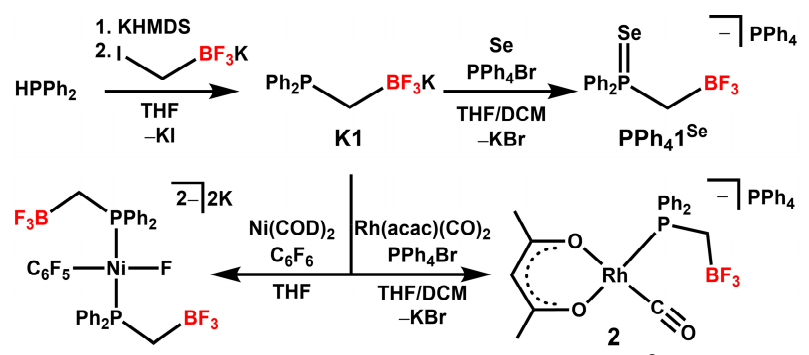

Scheme 1. Synthesis of $K 1$ and reactions to form $\left[\mathrm{PPh}_{4}\right]\left[1^{\mathrm{Se}}\right], 2$, and the proposed product of $\mathrm{C}-\mathrm{F}$ oxidative addition by a Ni complex featuring 1 . 

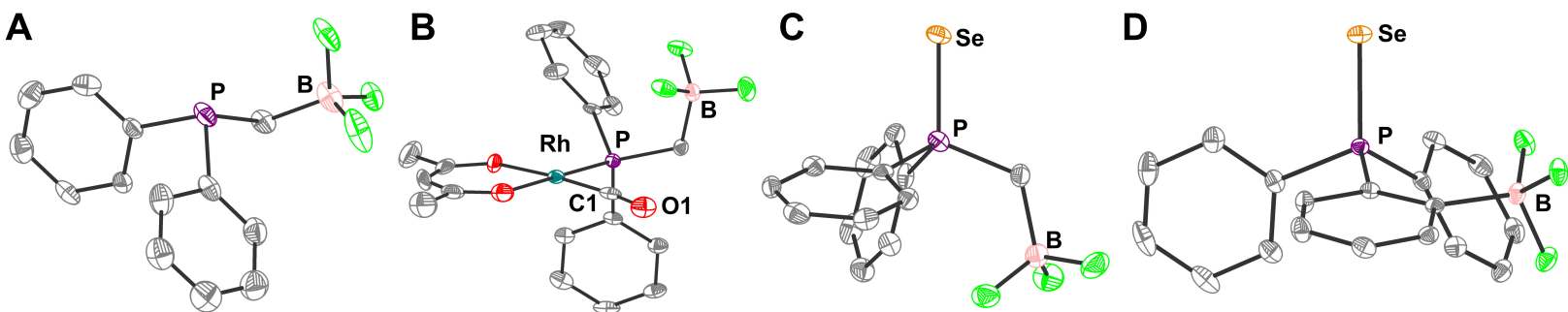

Figure 1. SXRD structures of the anions of $A) \mathrm{K} 1$, B) 2 , C) $\left[\mathrm{PPh}_{4}\right]\left[1^{\mathrm{Se}}\right]$, and $\left.\mathrm{D}\right)\left[\mathrm{PPh}_{4}\right]\left[3^{\mathrm{Se}}\right]$ with ellipsoids at $50 \%$ and $\mathrm{H}$-atoms and counterions omitted for clarity. $C$ is shown in grey, $O$ in red, $F$ in bright green, and other atom types are labeled. Selected bond lengths and angles (averaged where appropriate): (A) $B \cdots P$

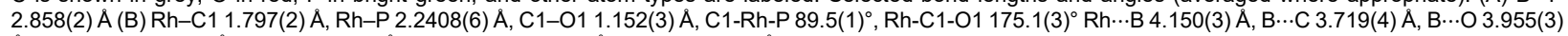

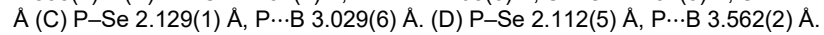

preclude convoluting resonance influences that might be expected in aryl linkers.

With these considerations in mind, the anionic phosphine $\mathrm{Ph}_{2} \mathrm{PCH}_{2} \mathrm{BF}_{3}^{-}$(1) was targeted as a new scaffold to investigate the relative contributions of through-bond and through-space effects (Scheme 1). Here we report the synthesis of this phosphine, quantification of the electrostatic impact on its donor properties via both solvent dependent NMR coupling constants of its phosphine selenide $\mathrm{Se}=\mathrm{PPh}_{2} \mathrm{CH}_{2} \mathrm{BF}_{3}{ }^{-} \quad\left(1^{\mathrm{Se}}\right)$ and its complexation to $\mathrm{Rh}$ carbonyls to give $\left[\mathrm{PPh}_{4}\right]\left[\mathrm{Rh}(\mathrm{acac})(\mathrm{CO})\left(\mathrm{PPh}_{2}\left(\mathrm{CH}_{2} \mathrm{BF}_{3}\right)\right)\right](2)$. We also extend these studies to an additional anionic phosphine selenide $\mathrm{Se}=\mathrm{PPh}_{2}(2-$ $\left.\mathrm{BF}_{3} \mathrm{Ph}\right)^{-}\left(3^{\mathrm{Se}}\right)$ with a longer and more rigid aryl linker. ${ }^{[84,85]}$ Our results show that electrostatic interactions are the dominant contributor to phosphine donor strength in these examples. Furthermore, we demonstrate that these electrostatic interactions in $\mathrm{K} 1$ can be leveraged for a $\sim 600$ fold acceleration of oxidative addition reactivity by the corresponding nickel complex, consistent with theoretical predictions. ${ }^{[60]}$ Finally, this accelerated reactivity enables the rapid catalytic defluoroborylation of comparatively electron-rich fluoroarenes. These studies illustrate that electrostatic interactions from charged functional groups are a major factor for donor strength in common organic solvents and that these electrostatic effects can be leveraged for increased oxidative addition reactivity and catalysis.

\section{Results and Discussion}

\section{Synthesis and Characterization of $\mathrm{Ph}_{2} \mathrm{PCH}_{2} \mathrm{BF}_{3} \mathrm{~K}(\mathrm{~K} 1)$}

Synthesis of the phosphine proceeds readily via deprotonation of $\mathrm{Ph}_{2} \mathrm{PH}$ with KHMDS (KHMDS = potassium hexamethyldisilazide), followed by dropwise addition to a stirring THF solution of potassium iodomethyltrifluoroborate (Scheme 1). The reaction was monitored by ${ }^{31} \mathrm{P}\left\{{ }^{1} \mathrm{H}\right\} \mathrm{NMR}$, and growth of a quartet at -15 ppm confirmed the formation of $\mathrm{PPh}_{2} \mathrm{CH}_{2} \mathrm{BF}_{3} \mathrm{~K}$ (K1) which is subsequently isolated as a white powder after workup. The ${ }^{1} \mathrm{H}$ NMR of K1 shows the expected aromatic signals for the phenyl groups, and a complicated doublet of quartets at $0.8 \mathrm{ppm}$ from coupling of the $\mathrm{CH}_{2}$ linker to phosphorus, boron, and fluorine. The ${ }^{31} \mathrm{P}\left\{{ }^{1} \mathrm{H}\right\}$ NMR spectrum shows coupling to fluorine with an identical chemical shift to that observed for $\mathrm{PPh}_{2} \mathrm{Et}$. This observation is consistent with previous reports that charged phosphines have similar shifts as their neutral analogues. ${ }^{[84,85,88]}$ Analysis by ${ }^{19} \mathrm{~F}\left\{{ }^{1} \mathrm{H}\right\}$ and ${ }^{11} \mathrm{~B}\left\{{ }^{1} \mathrm{H}\right\}$ NMR indicated the expected shifts and coupling for a $\mathrm{R}-\mathrm{BF}_{3}{ }^{-}$group, supporting the presence of this anionic unit. ${ }^{89]}$ Compound K1 was also structurally characterized via singlecrystal X-ray diffraction (SXRD, Figure 1A). The SXRD structure shows the expected connectivity and a close association between $\mathrm{K}$ and $\mathrm{B}$ of $\sim 3 \AA$. While it is unclear if this association is preserved

in solution, larger cations were chosen to limit ion pairing in further analyses (see below). The solid-state B...P distance is $2.858(2) \AA$ which serves as a proxy for the same distance in solution.

Tolman Electronic Parameter and $J_{P-S e}$ Determination

To assay the donor strength of $\mathbf{1}$, its Tolman Electronic Parameter (TEP) was determined using a Rh carbonyl complex of the form $\mathrm{Rh}(\mathrm{acac})(\mathrm{CO}) \mathrm{L}$, a safer alternative to $\mathrm{Ni}(\mathrm{CO})_{3} \mathrm{~L}$ complexes that are classically used for this measurement. ${ }^{[90]}$ Addition of K1 to $\mathrm{Rh}(\mathrm{acac})(\mathrm{CO})_{2} \quad$ with $\quad \mathrm{PPh}_{4} \mathrm{Br}$ furnished $\left[\mathrm{PPh}_{4}\right]\left[\mathrm{Rh}(\mathrm{acac})(\mathrm{CO})\left(\mathrm{PPh}_{2}\left(\mathrm{CH}_{2} \mathrm{BF}_{3}\right)\right)\right]$ (2) in good yield. Compound 2 was readily identified by ${ }^{31} \mathrm{P}\left\{{ }^{1} \mathrm{H}\right\}$ NMR spectroscopy from the appearance of a doublet of quartets arising from coupling of the phosphorus nuclei to ${ }^{103} \mathrm{Rh}$ with a $J_{\mathrm{P}-\mathrm{Rh}}$ of $166 \mathrm{~Hz}$. The SXRD structure of 2 shows a square planar geometry at Rh (Figure $1 \mathrm{~B}$ ). The $\mathrm{BF}_{3}$ unit is located significantly above the $\mathrm{Rh}$ square plane, and the $\mathrm{PPh}_{4}$ cation is not interacting with either the $\mathrm{BF}_{3}$ or the CO. The $\mathrm{B} \cdots \mathrm{C}$ and $\mathrm{B} \cdots \mathrm{O}$ distances are 3.719(4) and

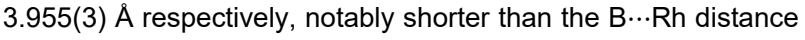
of $4.150(3) \AA$, although the difference diminishes upon normalizing to van der Waals radii (see $\mathrm{SI}$ ). The solution IR spectrum of 2 in $\mathrm{CH}_{2} \mathrm{Cl}_{2}$ shows a $v_{\mathrm{CO}}$ of $1965 \mathrm{~cm}^{-1}$, which correlates to a TEP of $2061 \mathrm{~cm}^{-1}$. This TEP is very similar to that of $\mathrm{P} P r_{3}$, which has a TEP of $2059 \mathrm{~cm}^{-1}$, and is significantly more donating than would be expected for an alkyldiaryl phosphine such as $\mathrm{PPh}_{2} \mathrm{Et}$, which has a TEP of $2066.7 \mathrm{~cm}^{-1}$ (Figure 2, dashed line). ${ }^{[74]}$ This result is consistent with the enhanced donation previously observed for phosphines with anionic borates. ${ }^{[75-88]}$

To further study the basicity and electron donation of 1 the corresponding phosphine selenide, $\left[\mathrm{PPh}_{4}\right]\left[\mathrm{Se}=\mathrm{PPh}_{2} \mathrm{CH}_{2} \mathrm{BF}_{3}\right]$ $\left(\left[\mathrm{PPh}_{4}\right]\left[1^{\mathrm{Se}}\right]\right)$, was prepared. Phosphorus-selenium coupling constants $\left(J_{\mathrm{P}-\mathrm{Se}}\right)$ have a linear correlation with the TEP of various phosphines, providing another measure of phosphine donor strength (black squares in Figure 2). ${ }^{[91,92]}$ The relationship between $J_{\text {P-Se }}$ and phosphine donor strength is best visualized by considering two limiting resonance structures for the phosphorus selenium bond, $\mathrm{Se}^{-}-\mathrm{P}^{+} \mathrm{R}_{3}$ and $\mathrm{Se}=\mathrm{PR}_{3}$. The zwitterionic resonance structure is favored by more donating $R$-groups and exhibits a lower JP-Se.

In order to prepare $\left[\mathrm{PPh}_{4}\right]\left[1^{\mathrm{Se}}\right], \mathrm{K} 1$ was stirred overnight in THF with an excess of elemental Se and $\mathrm{PPh}_{4} \mathrm{Br}$. The ${ }^{31} \mathrm{P}\left\{{ }^{1} \mathrm{H}\right\}$ NMR spectrum of $\left[\mathrm{PPh}_{4}\right]\left[\mathbf{1}^{\mathrm{Se}}\right]$ contains a quartet peak at $33 \mathrm{ppm}$, with satellite quartets at 31 and $35 \mathrm{ppm}$ from coupling to the ${ }^{77} \mathrm{Se}$ nucleus, and a singlet at $23 \mathrm{ppm}$ corresponding to $\mathrm{PPh}_{4}$. The SXRD structure of $\left[\mathrm{PPh}_{4}\right]\left[1^{\mathrm{Se}}\right]$ shows the $\mathrm{PPh}_{4}$ at a distance of $>6$ $\AA$ from $\mathrm{B}, \mathrm{P}$, or $\mathrm{Se}$, which suggests little to no interaction between the charged fragments in the solid state (Figure $1 \mathrm{C}$ and Figure S55). In DMSO- $d_{6}$, the $J_{P-S e}$ of $687 \mathrm{~Hz}$ is nearly identical to the $J_{P-}$ 


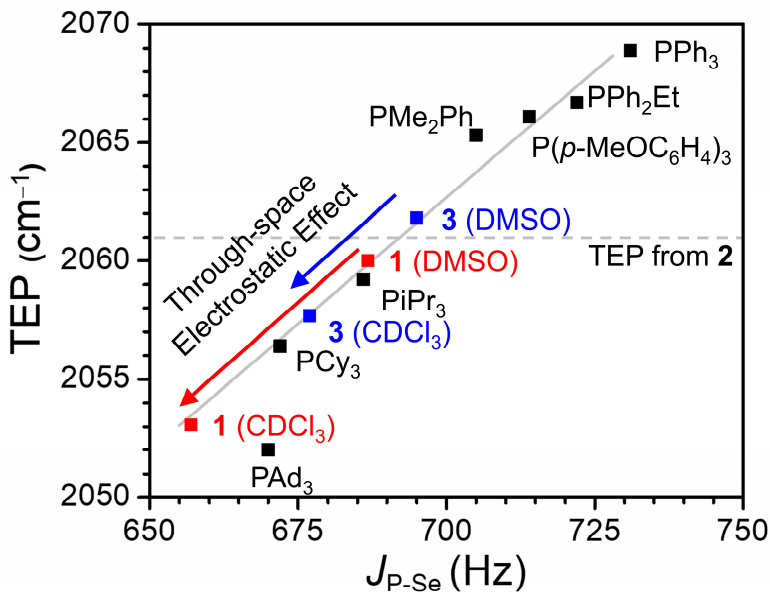

Figure 2. Correlation between the TEP of selected phosphine ligands and the $J_{p-S e}$ of their respective phosphine selenides (black squares, gray line is linear fit, dashed gray line is the TEP of $\mathbf{2}$ from IR spectroscopy). ${ }^{74,91,92}$ The TEP for 1 and 3 in DMSO- $d_{6}$ and $\mathrm{CDCl}_{3}$ is extrapolated using the $\mathrm{JP}_{\mathrm{P}-\mathrm{Se}}$ of $\left[\mathrm{PPh}_{4}\right]\left[1^{\mathrm{Se}}\right]$ and $\left[\mathrm{PPh}_{4}\right]\left[3^{\mathrm{Se}}\right]$ (red and blue squares respectively). The arrows indicate the estimated electrostatic effect.

se of $\mathrm{Se}=\mathrm{P}^{\mathrm{P} P r_{3}}$ reported in $\mathrm{CDCl}_{3} .{ }^{[91,92]}$ The $\mathrm{JP}_{\mathrm{P} \text {-Se }}$ determined via $\left[\mathrm{PPh}_{4}\right]\left[\mathbf{1}^{\mathrm{Se}}\right]$ in DMSO- $d_{6}$ and the TEP determined via complex 2 fits within the established correlation (Figure 2). This $J_{P-S e}$ value also indicates an increase in donor strength as compared to the neutral congener $\mathrm{Se}=\mathrm{PPh}_{2} \mathrm{Et}$, which has a $J_{\mathrm{P}-\mathrm{Se}}$ of $722 \mathrm{~Hz}$ in DMSO- $d_{6} \cdot{ }^{[91,92]}$ The TEP and $J_{P-S e}$ values indicate that the anionic charge promotes a large increase in the donor strength of $\left[\mathrm{PPh}_{4}\right]\left[1^{\mathrm{Se}}\right]$ relative to neutral analogues, even without a conjugated linker to the phosphine. Seeing this large change encouraged us to investigate whether there was a reasonable experimental technique to separate through-space electrostatic from through-bond inductive effects.

\section{Analysis of Electrostatic Effects}

We predicted that the through-space electrostatic influence of the charged group could be modified or screened by the solvent environment around the molecule, while the through-bond interactions would only be slightly affected by this variable. We expected that measuring $J_{\mathrm{P}-\mathrm{Se}}$ over a range of solvents with different dielectrics $(\varepsilon)$, a measure of a medium's ability to shield a charge ${ }^{[93]}$ would give rise to a range of coupling values. While inductive donor effects in $\left[\mathrm{PPh}_{4}\right]\left[1^{\mathrm{Se}}\right]$ should be insensitive to $\varepsilon$, the electrostatic stabilization of the zwitterionic resonance structure $\mathrm{Se}^{-}-\mathrm{P}^{+} \mathrm{R}_{3}$ by the adjacent $\mathrm{BF}_{3}$ anion should depend on $\varepsilon$, with higher $\varepsilon$ giving a lower electrostatic contribution and a higher $J_{\mathrm{P} \text {-Se }}$. It should be noted that previous literature studies demonstrate some solvent dependence to $J_{\mathrm{P}-\mathrm{Se}}$, with one report suggesting variation between $2-3 \%{ }^{[94,95]}$ In this analysis, comparison of $J_{\mathrm{P}-\mathrm{Se}}$ in the anionic phosphine to neutral analogues, examining the solvent dependence of these neutral analogues, and restricting the solvent choice to aprotic solvents serve as controls for any incidental trends.

The $J_{\mathrm{P}-\mathrm{Se}}$ of $\left[\mathrm{PPh}_{4}\right]\left[{ }^{\mathrm{Se}}\right]$ was therefore measured in solvents with a range of $\varepsilon$. An overall decrease of $30 \mathrm{~Hz}$ was observed upon moving to from DMSO- $d_{6}$ to $\mathrm{CDCl}_{3}$, indicating that throughspace electrostatic effects are a significant contributor to the donor properties of 1 (Figure 3, Figure S52, and Table S6). In comparison, a slight change of $7 \mathrm{~Hz}$ is observed across the same $\varepsilon$ range for the neutral congener $\mathrm{Se}=\mathrm{PPh}_{2} \mathrm{Et}$ (Figure 3, Figure S52,
Table S6). Coulomb's law suggests that a linear dependence on $1 /(4 \pi \varepsilon)$ would be expected for a primarily electrostatic effect. Indeed, the observed solvent dependence of $J_{\text {P-Se }}$ for $\left[\mathrm{PPh}_{4}\right]\left[1^{\mathrm{Se}}\right]$ follows this trend; the variable solvent coupling data are well fit $\left(R^{2}=0.98\right)$ to the linear relationship $J_{\mathrm{P}-\mathrm{Se}}=693(1)$ $2.12(12)^{*} 103^{*}(1 /(4 \pi \varepsilon))$. While ion pairing should increase in low dielectric solvents and could thus impact the observed trends, the solid-state structure of $\left[\mathrm{PPh}_{4}\right]\left[1^{\mathrm{Se}}\right]$ indicates there is little interaction with $\mathrm{PPh}_{4}{ }^{+}$(Figure $1 \mathrm{C}$ and Figure S55). Furthermore, control experiments with excess $\mathrm{PPh}_{4} \mathrm{Br}$ in $\mathrm{CH}_{2} \mathrm{Cl}_{2}$ showed only small changes to $J_{P-S e}(<7 \mathrm{~Hz}$, Figure $S 25)$.

In addition to using $J_{\mathrm{P}-\mathrm{Se}}$ to measure electrostatic contributions, we also attempted to measure these contributions via IR spectroscopy. However, IR spectra of $\mathbf{2}$ and $\mathrm{Rh}(\mathrm{CO})_{2}$ (acac) in MeCN, THF, and DCM show no variation of $v_{\mathrm{CO}}$ outside of instrumental error (Figures S44 and S45). This is perhaps not surprising as the expected change in stretching frequency of $\sim 10$ $\mathrm{cm}^{-1}$ is not large compared to the instrumental resolution $\left(4 \mathrm{~cm}^{-1}\right)$. Resolving dielectric induced shifts is further limited by spectral convolution or broadening, likely from $\mathrm{Rh}-\mathrm{P}$ rotational isomers of 2 with different stretching frequencies as has been observed in other carbonyl systems. ${ }^{[96]}$ This manifests as substantially broader spectra for 2 versus $\mathrm{Rh}(\mathrm{CO})_{2}(\mathrm{acac})$. For these reasons, $J_{P-S e}$ serves as a better metric for examining through-space electrostatic effects in the current system.

The high $\varepsilon$ and vacuum limits obtained from the linear fits provide us with the ability to determine the electrostatic contribution to the increase in donor strength of $\left[\mathrm{PPh}_{4}\right]\left[1^{\mathrm{Se}}\right]$ as compared to $\mathrm{PPh}_{2}$ Et. Simply shifting from the high $\varepsilon$ limit $(693 \mathrm{~Hz})$ to the vacuum limit $(524 \mathrm{~Hz})$ of $\left[\mathrm{PPh}_{4}\right]\left[1^{\mathrm{Se}}\right]$ yields an overall change in coupling of $169 \mathrm{~Hz}$. Comparison of this electrostatic shift with the $207 \mathrm{~Hz}$ difference in coupling between the vacuum limit of $\left[\mathrm{PPh}_{4}\right]\left[1^{\mathrm{Se}}\right](524 \mathrm{~Hz})$ and the high $\varepsilon$ limit of $\mathrm{PPh}_{2} \mathrm{Et}(731$ $\mathrm{Hz}$ ) provides an estimated electrostatic contribution of $82 \%$ of the total increase in donor strength (Table 1). While this analysis uses the extrapolated limits, the experimental data from the accessible range of $\varepsilon$ also suggest that the electrostatic contribution is at least $50 \%$. These analyses show that electrostatic factors have a

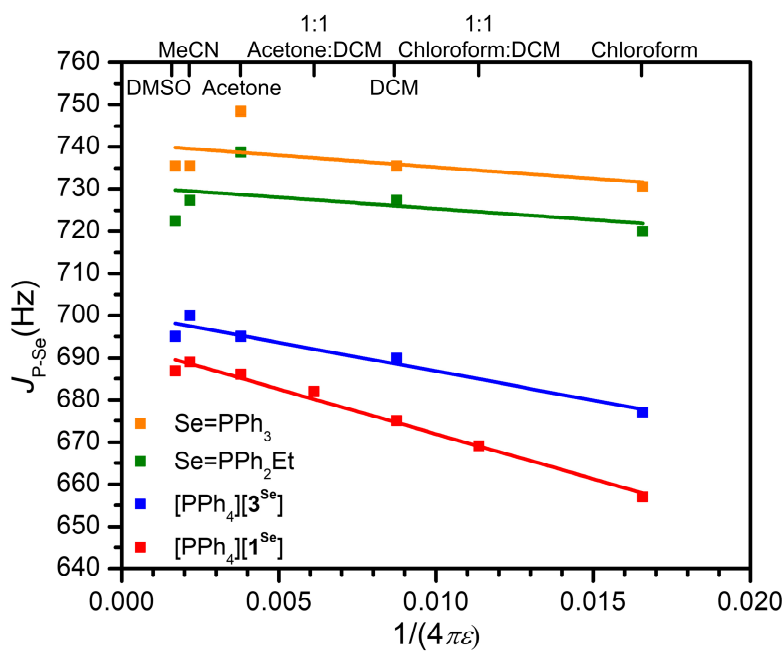

Figure 3. Solvent dependence of $J_{\mathrm{P}-\mathrm{Se}}$ for anionic and neutral phosphines. Linear fits are shown as lines. The fit data for $\left[\mathrm{PPh}_{4}\right]\left[1^{\mathrm{Se}}\right]$ is provided in the text, and the fit data for $\left[\mathrm{PPh}_{4}\right]\left[3^{\mathrm{Se}}\right]$ is $\mathrm{R}^{2}=0.92$, JP-Se $=700(2)-1.4(2)^{*} 10^{3 *}(1 /(4 \pi \varepsilon))$. Further discussion of the fits is provided in the SI. Different dielectrics $(\varepsilon)$ were generated with $\mathrm{CDCl}_{3}, \mathrm{CD}_{2} \mathrm{Cl}_{2}$, acetone- $d_{6}, \mathrm{CD}_{3} \mathrm{CN}$, DMSO- $d_{6}$, or mixtures thereof (see Table S6) 
Table 1. Experimental (A.) and Computational (B.) JP-Se Coupling Constrants as a Function of Charge and Dielectric

\begin{tabular}{lcc}
\hline A. & $\mathrm{R}=\mathrm{Et} ; \mathbf{X}=\mathbf{1}$ & $\mathrm{R}=\mathrm{Ph} ; \mathbf{X}=\mathbf{3}$ \\
\hline $\mathrm{Se}=\mathrm{PPh}_{2} \mathrm{R}$ & $731 \mathrm{~Hz}$ & $741 \mathrm{~Hz}$ \\
$\left(\varepsilon=\infty, J_{\text {neutral }}\right)$ & $693 \mathrm{~Hz}$ & $700 \mathrm{~Hz}$ \\
{$[\mathrm{PPh} 4]\left[\mathbf{X}^{\mathrm{Se}}\right]$} & & \\
$\left(\varepsilon=\infty, J_{\infty}\right)$ & $524 \mathrm{~Hz}$ & $591 \mathrm{~Hz}$ \\
{$[\mathrm{PPh}]\left[\mathbf{X}^{\mathrm{Se}}\right]$} & $-38 \mathrm{~Hz}$ & $-41 \mathrm{~Hz}$ \\
$\left(\varepsilon=1, J_{\text {vac }}\right)$ & $-169 \mathrm{~Hz}$ & $-109 \mathrm{~Hz}$ \\
$\Delta J_{\text {covalent }}=J_{\infty}-J_{\text {neutral }}$ & $-207 \mathrm{~Hz}$ & $-150 \mathrm{~Hz}$ \\
$\Delta J_{\text {electrostatic }}=J_{\text {vac }}-J_{\infty}$ & & \\
$\Delta J_{\text {tot }}=J_{\text {vac }}-J_{\text {neutral }}$ & 0.82 & 0.73 \\
\hline Relative contributions to $\Delta \mathbf{J}$ & 0.18 & 0.27 \\
\hline$\Delta J_{\text {electrostatid }} \Delta J_{\text {tot }}$ &
\end{tabular}

\begin{tabular}{ll}
\hline BFT & \\
\hline SePPh & Et \\
$\left(\varepsilon=1, J_{\text {neutral }}\right)$ & $872 \mathrm{~Hz}$ \\
SePPh $E$ Et & $809 \mathrm{~Hz}$ \\
$\left(\right.$ point charge, $\left.\varepsilon=1, J_{\text {point }}\right)$ & \\
{$\left[\mathrm{PPh}_{4}\right]\left[\mathbf{1}^{\mathrm{Se}}\right]$} & $792 \mathrm{~Hz}$ \\
$\left(\varepsilon=1, J_{\text {anion }}\right)$ & $-17 \mathrm{~Hz}$ \\
$\Delta J_{\text {covalent }}=J_{\text {anion } \infty}-J_{\text {point }}$ & $-63 \mathrm{~Hz}$ \\
$\Delta J_{\text {electrostatic }}=J_{\text {point }}-J_{\text {neutral }}$ & $-80 \mathrm{~Hz}$ \\
$\Delta J_{\text {tot }}=J_{\text {anion }}-J_{\text {neutral }}$ & \\
\hline Relative contributions to $\Delta \mathbf{J}$ & 0.79 \\
\hline$\Delta J_{\text {electrostatid } / \Delta J_{\text {tot }}}$ & 0.21 \\
\hline$J_{\text {covalent }} / \Delta J_{\text {tot }}$ &
\end{tabular}

major, and even dominant, impact on the donor properties in these systems.

\section{Computational Analysis}

To further investigate the relative contribution of through-space versus through-bond effects, Density Functional Theory (DFT) calculations with the B3P functional were performed to estimate $J_{\text {P-Se }}$ and compare with experimentally determined values (Table 1). Two optimized local geometries of $\mathbf{1}^{\text {se }}$ were considered as the structure is likely fluxional during the solution NMR experiments. Both configurations have similar B...P distances (3.11 and 3.05 $\AA$, Figure 4, left and right respectively). However, in the first geometry the $\mathrm{BF}_{3}$ is located closer to the $\mathrm{P}=\mathrm{Se}$ bond axis, with a Se-P-C-B dihedral of $158^{\circ}$ (Figure 4, left). In the second geometry, which is higher in energy by $3.4 \mathrm{kcal} / \mathrm{mol}$, the $\mathrm{BF}_{3}$ group is farther, with a Se-P-C-B dihedral of $74^{\circ}$ (Figure 4 , right). These transoid and cisoid structures were considered as configurations of $1^{\text {Se }}$ that represent the limit of Se...P distances that may be present in solution, with the assumption that other configurations would be intermediate between these two. The coupling calculated for the cisoid structure of $1^{\text {Se }}$ was $849 \mathrm{~Hz}$ while the coupling in the transoid structure was calculated to be $792 \mathrm{~Hz}$. Taking a Boltzmann weighted average of these two extremes gives a predicted average $J_{\mathrm{P}-\mathrm{Se}}$ of $\sim 792 \mathrm{~Hz}$. While the absolute value of this predicted coupling is far from the experimentally determined one, this analysis is still useful for comparing trends with other DFT determined values. More importantly, the DFT predicted $J_{P-S e}$ couplings emphasize that charge location has a large effect.

To explicitly analyze electrostatic contributions to coupling values, we used Coulomb's law to estimate the electric field at $P$ in $1^{\text {Se }}$ generated by a negative point charge located at the boron atom. This analysis on the calculated structures of $1^{\text {Se }}$ gives a Boltzmann weighted electric field parallel to the $\mathrm{P}=\mathrm{Se}$ bond (defined as the Z-axis) of -1.07 VIA (Table S3). The magnitude of $J_{P \text {-Se }}$ for a neutral analogue of $1^{\mathrm{Se}}, \mathrm{Se}=\mathrm{PPh}_{2} \mathrm{Et}$, was then calculated by DFT in the presence of this same field as generated by a point charge at $\sim-3.7 \AA$ in the $Z$ direction from the $\mathrm{P}$ atom. The inclusion of this point charge lowers $J_{P-S e}$ from the neutral analogue by $63 \mathrm{~Hz}$, from $872 \mathrm{~Hz}$ to $809 \mathrm{~Hz}$. The percentage of the decrease in $J_{P-S e}$ is identical within error to that determined experimentally, $79 \%$. These DFT calculations support the experimental data demonstrating that electrostatic effects play a significant role in the donor properties of 1.

Extension and Comparison to Other Phosphines

The selenide of an anionic phosphine previously investigated for $\mathrm{Pd}$ catalyzed olefin polymerization/oligomerization, $\left[\mathrm{PPh}_{4}\right]\left[\mathrm{Se}=\mathrm{PPh}_{2}\left(2-\mathrm{BF}_{3} \mathrm{Ph}\right)\right] \quad\left(\left[\mathrm{PPh}_{4}\right]\left[3^{\mathrm{Se}}\right]\right)$, was analogously synthesized. This phosphine was targeted to test the generality of this solvent-dependence analysis of electrostatic contributions to donor properties, particularly in the presence of increased rigidity and possible convoluting resonance effects from an aryl linker. ${ }^{[84,85]}$ The SXRD structure of $\left[\mathrm{PPh}_{4}\right]\left[3^{\mathrm{Se}}\right]$ confirms the expected connectivity and also shows that the $\mathrm{BF}_{3}$ group is farther from the phosphine than in $\left[\mathrm{PPh}_{4}\right]\left[1^{\mathrm{Se}}\right]$ (Figure 1D, 3.562(2) and 3.029(6) $\AA$ respectively). The $\mathrm{PPh}_{4}{ }^{+}$cation is still well separated at 5.895(2) $\AA$, suggesting minimal ion pairing (Figure S56).

The solvent dependence of $J_{\mathrm{P}-\mathrm{Se}}$ for $\left[\mathrm{PPh}_{4}\right]\left[3^{\mathrm{Se}}\right]$ was then measured with the related assumption that inductive and resonance contributions along the covalent linkage would be predominantly independent of solvent dielectric screening. The $J_{\mathrm{P}-\mathrm{Se}}$ of $\left[\mathrm{PPh}_{4}\right]\left[3^{\mathrm{Se}}\right]$ exhibits a solvent dependence similar to that of $\left[\mathrm{PPh}_{4}\right]\left[1^{\mathrm{Se}}\right]$ (Figure 3, Figure S52, and Table S6). The overall difference upon moving from DMSO- $d_{6}$ to $\mathrm{CDCl}_{3}$ is $18 \mathrm{~Hz}$, smaller than the $30 \mathrm{~Hz}$ shift observed for $\left[\mathrm{PPh}_{4}\right]\left[1^{\mathrm{Se}}\right]$. Furthermore, the magnitude of the slope of the linear fit to the solvent dependence for $\left[\mathrm{PPh}_{4}\right]\left[3^{\mathrm{Se}}\right]$ is $\sim 70 \%$ of that for $\left[\mathrm{PPh}_{4}\right]\left[1^{\mathrm{Se}}\right]$. This is consistent with the ratio predicted from a $1 /\left(r^{2}\right)$ dependence from Coulomb's law based on the relative $\mathrm{B} \cdots \mathrm{P}$ distances in $\left[\mathrm{PPh}_{4}\right]\left[3^{\mathrm{Se}}\right]$ and $\left[\mathrm{PPh}_{4}\right]\left[1^{\mathrm{Se}}\right]$ from SXRD (3.562(2) and 3.029(6) A respectively, $72 \%$, see $\mathrm{SI}$ ).

The neutral congener of $\left[\mathrm{PPh}_{4}\right]\left[3^{\mathrm{Se}}\right], \mathrm{Se}=\mathrm{PPh}_{3}$, was also prepared and similarly to $\mathrm{Se}=\mathrm{PPh}_{2} \mathrm{Et}$ shows only a slight change in coupling constant with differing $\varepsilon$, shifting only $5 \mathrm{~Hz}$ upon switching from $\mathrm{CDCl}_{3}$ to DMSO- $d_{6}$ (Figure 3 ). Using the $J_{\mathrm{P} \text {-Se }}$ values from the high $\varepsilon$ and vacuum limits determined from the linear fit of $\left[\mathrm{PPh}_{4}\right]\left[3^{\mathrm{Se}}\right]$ and an identical comparison method to that described above suggests an electrostatic contribution to the overall shift of $73 \%$, which is still slightly smaller than that for $\left[\mathrm{PPh}_{4}\right]\left[1^{\mathrm{Se}}\right](82 \%)$. In sum, all the experimental data acquired on both $\left[\mathrm{PPh}_{4}\right]\left[1^{\mathrm{Se}}\right]$ and $\left[\mathrm{PPh}_{4}\right]\left[3^{\mathrm{Se}}\right]$ support a significant and potentially major role that through-space electrostatic interactions have in the donor properties of these phosphines, and furthermore illustrate that $J_{\mathrm{P}-\mathrm{Se}}$ is a useful probe for deconvoluting electrostatic from inductive or resonance effects.
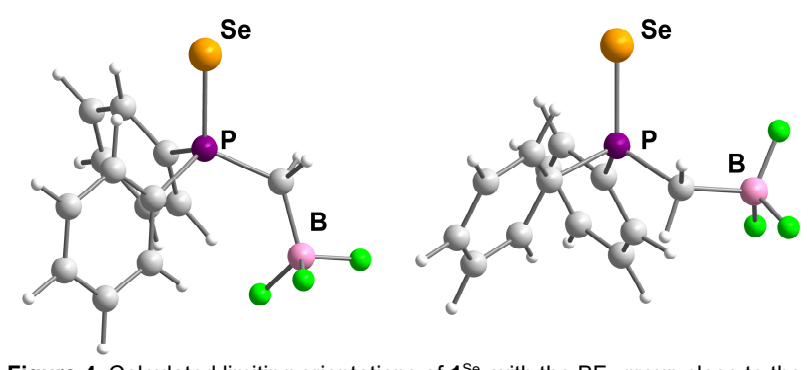

Figure 4. Calculated limiting orientations of $1^{\mathrm{Se}}$, with the $\mathrm{BF}_{3}$ group close to the $\mathrm{P}=$ Se axis (left, transoid) and the $\mathrm{BF}_{3}$ group far from the $\mathrm{P}=\mathrm{Se}$ axis (right, cisoid). 
Comparing the overall shifts in $J_{\mathrm{P}-\mathrm{Se}}$ from $\left[\mathrm{PPh}_{4}\right]\left[1^{\mathrm{Se}}\right]$ and $\left[\mathrm{PPh}_{4}\right]\left[3^{\mathrm{Se}}\right]$ from their respective neutral congeners to other anionic phosphine systems is instructive, even in the absence of comparable solvent dependence studies. In one example a triptycene borate phosphine with a P...B distance of $3.03 \AA$ was compared to a silicon based neutral analog. ${ }^{[79,80]}$ The shift in $J_{P \text {-Se }}$ observed in $\mathrm{CDCl}_{3}$ upon switching from the neutral to anionic version approached $90 \mathrm{~Hz}$. The magnitude of this shift is larger than the $63 \mathrm{~Hz}$ shift observed between $\left[\mathrm{PPh}_{4}\right]\left[1^{\mathrm{Se}}\right]$ and $\mathrm{Se}=\mathrm{PPh}_{2} \mathrm{Et}$ and the $54 \mathrm{~Hz}$ difference observed between $\left[\mathrm{PPh}_{4}\right]\left[3^{\mathrm{Se}}\right]$ and $\mathrm{Se}=\mathrm{PPh}_{3}$ in $\mathrm{CDCl}_{3}$. The greater magnitude of the shift can be rationalized by the orientation of the anionic functional group, which is constrained to align with the $\mathrm{P}=\mathrm{Se}$ bond in the triptycene case, as well as exclusion of solvent screening by the triptycene cage. The significant change in $J_{P-S e}$ coupling observed in the triptycene case contrasts with another example featuring an anionic $\mathrm{PhBPh}_{3}$ group, $\mathrm{Se}=\mathrm{PPh}_{2}\left(p-\mathrm{BPh}_{3} \mathrm{Ph}\right)^{-} \cdot{ }^{[88]}$ The difference in coupling between this compound and the neutral congener $\mathrm{Se}=\mathrm{PPh}_{3}$ is only $30 \mathrm{~Hz}$ in $\mathrm{CDCl}_{3}$, likely due to the larger distance between the charged group and the phosphine $(6.49 \AA$ from DFT). ${ }^{[8]}$ Comparison of these examples illustrates that the distance, orientation, and structural protection of charged groups from screening dictates the magnitude of their impact on phosphine donor properties.

\section{Reactivity}

Challenging oxidative addition reactions were then targeted as a final test of the effect that negative charges have on phosphine donor properties. Local electric fields generated by ionic additives have recently been calculated to lower the barriers for oxidative addition of $\mathrm{C}-\mathrm{F}$ bonds mediated by a $\mathrm{PMe}_{3}$ supported $\mathrm{Pd}$ complex and motivated the study of similar reactivity with $\mathrm{K} 1$. $^{[60]}$ Oxidative addition of hexafluorobenzene has been reported with $\mathrm{Ni}(\mathrm{COD})_{2}$ and $\mathrm{PEt}_{3}$ in hexane (COD = 1,5-cyclooctadiene), but this reaction requires four weeks to reach completion at room temperature. ${ }^{[97]}$ As $\mathrm{PEt}_{3}$ and $\mathrm{K} 1$ have similar TEP values $\left(2061.7\right.$ and $2061 \mathrm{~cm}^{-1}$ respectively) and cone angles ( 132 and $140^{\circ}$ for $\mathrm{PEt}_{3}$ and $\mathrm{PPh}_{2} \mathrm{Et}$ ), this reaction was selected as a good test case to see if the anionic charge of $\mathrm{K} 1$ would accelerate oxidative addition as has been predicted. ${ }^{[60,74]}$

Performing this reaction with $\mathrm{K} 1$ instead of $\mathrm{PEt}_{3}$ in THF resulted in formation of the $\mathrm{C}-\mathrm{F}$ oxidative addition product with a $k_{\text {obs }}$ of $-6.3 \mathrm{E}-4 \mathrm{~s}^{-1}$, resulting in complete consumption of the starting complex within 70 minutes, $\sim 600$ times faster than with $\mathrm{PEt}_{3}$ (Scheme 1). The oxidative addition product was confirmed by characteristic ${ }^{19} \mathrm{~F}$ peaks for the $\mathrm{Ni}-\mathrm{F}$ and the $\mathrm{C}-\mathrm{F}$ ortho to the metal center as well as a single new ${ }^{31} \mathrm{P}$ peak (Figures S29S31). ${ }^{[97]}$ Monitoring the reaction by UV-vis spectroscopy also indicated full consumption of the starting material after one hour (Figure S46). Monitoring the absorbance of the complex without $\mathrm{C}_{6} \mathrm{~F}_{6}$ indicates minimal decay (Figure S47).

The significant rate acceleration observed in stoichiometric reactivity led us to pursue catalytic $\mathrm{C}-\mathrm{F}$ borylation with $\mathrm{K} 1$ and $\mathrm{Ni}(\mathrm{COD})_{2}$. Defluoroborylation of fluorinated arenes with $\mathrm{Ni}$ has been reported previously with $\mathrm{N}$-heterocyclic carbene and tricyclohexylphosphine ligands. ${ }^{[98-100]}$ The use of strongly donating ligands is consistent with the difficulty of the oxidative addition step, as C-F bonds have the highest BDE among carbon-halogen bonds. ${ }^{[98]}$ Optimization reactions were carried out with 1,3-difluorobenzene as the test substrate, and ultimately a $50 \%$ yield of $1-\mathrm{Bpin}-3-\mathrm{C}_{6} \mathrm{FH}_{4}$ was realized with the final reaction conditions of a $9 \%$ catalyst loading with 1.8 equivalents of bis(pinacolato)diboron $\left(\mathrm{B}_{2} \mathrm{pin}_{2}\right), 0.9$ equivalents of $\mathrm{CsOH}$, and 1.8 equivalents of methanol in THF heated at $50{ }^{\circ} \mathrm{C}$ for 4 hours (Tables S10-S14 contain optimization conditions). Notably, substituting $\mathrm{K} 1$ for $\mathrm{PEt}_{3}, \mathrm{PCy}_{3}$, or $\mathrm{PPh}_{2} \mathrm{Et}$ under identical reaction conditions resulted in no appreciable conversion to the borylated product. Additionally, heating the reaction for 6 hours did not increase yield. Optimization studies indicate that both the Cs counterion and the hydroxide/alkoxide nucleophiles are required for the reaction, considering that neither TMAOH nor CsF showed appreciable catalysis (Tables S10-S14). Although fluoride and phenoxide sources have been used previously to accelerate transmetalation with $\mathrm{B}_{2} \mathrm{pin}_{2}$, in this case a stronger nucleophile was required. ${ }^{[100]}$ We speculate that the success of $\mathrm{CsOH}$ and alcohols in this reaction is likely a result of the formation of a trialkoxy borate from $\mathrm{B}_{2} \mathrm{pin}_{2}$, as tri-alkoxy borates have comparatively higher Mayr nucleophilicity values. ${ }^{[101]}$

This optimized method was then extended to other fluoroarenes (Figure 5), and the yields decrease with higher levels of fluorination. Of interest is that this reactivity trend with $\mathrm{K} 1$ results in comparatively higher yields for sparsely fluorinated substrates such as fluorobenzene and 1,3-difluorobenzene as compared with a previously reported system which utilizes a strongly donating $\mathrm{N}$-heterocyclic carbene ligand. ${ }^{[100]}$ Furthermore, this previous example used excess fluoroarene and a limiting amount of $\mathrm{B}_{2} \mathrm{pin}_{2}$. In contrast, our system exhibits better yields with limiting fluoroarene, as has been observed with other phosphine supported catalysts. ${ }^{[100]}$ Finally, we note the that substrates with ortho-fluorine atoms exhibit a substantial preference towards homocoupling over borylation, possibly as a result of competing reaction between the oxidative addition intermediate and the borylated product.

The differing reactivity trends between the current catalytic system and previous examples lead us to propose that the enhanced oxidative addition rate in the present system makes transmetalation the turnover limiting step. This hypothesis is consistent with increased yields with an excess of $\mathrm{B}_{2} \mathrm{pin}_{2}$ as well as the enhanced yields with hydroxide or alkoxide over fluoride sources. Additionally, the unique reactivity of $\mathrm{K} 1$ compared to neutral phosphines of comparable or greater TEP supports

\begin{tabular}{|c|c|c|}
\hline \multirow{2}{*}{$A r^{F}-F$} & $\begin{array}{c}\mathrm{Ni}(\mathrm{COD})_{2}(9 \%) \\
\mathrm{K} 1(18 \%)\end{array}$ & \multirow{2}{*}{$-A r^{\mathrm{F}}-\mathrm{Bp}$ in $+A r^{\mathrm{F}}-\mathrm{Ar}^{\mathrm{F}}$} \\
\hline & $\begin{array}{c}\text { B }_{2} \text { pin }_{2}(1.8 \text { eq. }) \\
\text { OH (0.9 eq.), MeOH }(0.9 \\
\text { THF, } 50^{\circ} \mathrm{C}, 4 \text { hours }\end{array}$ & \\
\hline Substrate & Yield borylated product & Yield coupled product \\
\hline $\mathrm{C}_{6} \mathrm{H}_{5} \mathrm{~F}$ & $\mathrm{C}_{6} \mathrm{H}_{5} \mathrm{Bpin}(42 \%)^{\mathrm{a}}$ & $\mathrm{n} / \mathrm{a}$ \\
\hline $1,2-\mathrm{C}_{6} \mathrm{~F}_{2} \mathrm{H}_{4}$ & 1-Bpin-2- $\mathrm{C}_{6} \mathrm{FH}_{4}(14 \%)$ & $2,2^{\prime}-\mathrm{F}_{2}-1,1^{\prime}-\mathrm{Ph}_{2}(56 \%)$ \\
\hline $1,3-\mathrm{C}_{6} \mathrm{~F}_{2} \mathrm{H}_{4}$ & 1-Bpin-2- $\mathrm{C}_{6} \mathrm{FH}_{4}(50 \%)$ & $\mathrm{n} / \mathrm{a}$ \\
\hline $1,4-\mathrm{C}_{6} \mathrm{~F}_{2} \mathrm{H}_{4}$ & 1-Bpin-4- $\mathrm{C}_{6} \mathrm{FH}_{4}(21 \%)$ & $\mathrm{n} / \mathrm{a}$ \\
\hline $1,2,4-\mathrm{C}_{6} \mathrm{~F}_{3} \mathrm{H}_{3}$ & $\mathrm{n} / \mathrm{a}$ & $2,2^{\prime}, 5,5^{\prime}-\mathrm{F}_{4}-1,1^{\prime}-\mathrm{Ph}_{2}(29 \%)$ \\
\hline $1,3,5-\mathrm{C}_{6} \mathrm{~F}_{3} \mathrm{H}_{3}$ & $\begin{array}{l}\text { 1-Bpin-3,5- } \mathrm{C}_{6} \mathrm{~F}_{2} \mathrm{H}_{3}(20 \%) \\
\text { 1,3-Bpin-5- } \mathrm{C}_{6} \mathrm{FH}_{3}(18 \%)\end{array}$ & $\mathrm{n} / \mathrm{a}$ \\
\hline
\end{tabular}

Figure 5. Substrate scope of $\mathrm{C}-\mathrm{F}$ oxidative addition. Unless otherwise specified, all reactions were carried out in $1 \mathrm{~mL}$ of THF with $\mathrm{Ni}(\mathrm{COD}) 2(10 \mathrm{mg}$, $0.036 \mathrm{mmol}), \mathrm{K} 1(22 \mathrm{mg}, 0.072 \mathrm{mmol}), \mathrm{B}_{2} \mathrm{pin}_{2}(184 \mathrm{mg}, 0.72 \mathrm{mmol}), \mathrm{CsOH}$ (54mg, $0.36 \mathrm{mmol}), \mathrm{MeOH}(30 \mu \mathrm{L}, 0.72 \mathrm{mmol}), \mathrm{CF}_{3} \mathrm{Ph}(20,0.16 \mathrm{mmol})$, and the substrate $(0.4 \mathrm{mmol})$, and were heated with stirring for 4 hours at $50{ }^{\circ} \mathrm{C}$. All yields unless otherwise specified are relative to added substrate and were determined by comparison to an internal $\mathrm{CF}_{3} \mathrm{Ph}$ integral standard. (a) Yield determined using GCMS. For more details see SI. 
electrostatic acceleration of the oxidative addition by the triflurooborate anion, consistent with theoretical predictions. While speculative, this proposal underscores the importance of the charged group. The fact that the inclusion of the trifluoroborate group enables a diarylalkyl phosphine to perform comparably with a $\mathrm{N}$-heterocyclic carbene in $\mathrm{C}-\mathrm{F}$ borylation highlights how electrostatic effects can both dramatically enhance stoichiometric oxidative addition reactivity as well as tune catalytic processes.

\section{Conclusion}

In conclusion, we have generated a new phosphine ligand and demonstrated that the inclusion of an anionic trifluoroborate group dramatically increases its donor properties relative to neutral analogues. Furthermore, through a series of experiments and calculations we have demonstrated that a major portion of the increase in donor strength arises from electrostatic as opposed to inductive effects. The electrostatic interactions in this ligand enable large acceleration of oxidative addition rates in comparison to a ligand of comparable donor strength, consistent with proposals from computational investigations. This enhanced oxidative addition reactivity can be leveraged for catalytic borylation of $\mathrm{C}-\mathrm{F}$ bonds with differing reactivity trends to previously reported examples. While there are several reports where the influence of appended anionic groups on mono- or polydentate phosphine ligands have been explored, this work is the first case where the relative contributions from inductive versus electrostatic donation have been disentangled. Furthermore, this study represents a rare system where the relative impact of through-bond and through-space interactions can be discerned. The ability of charged groups to stabilize specific resonance structures, such as the zwitterionic $\mathrm{Se}^{-}-\mathrm{P}^{+} \mathrm{R}_{3}$ structure, offers tremendous potential in tuning catalytic systems as we demonstrate here. The fact that a major portion of the increase in donor strength arises from electrostatic effects in common organic solvents has important implications for ligand design as the directionality of electric fields provides a unique variable for influencing reactivity and breaking classic free-energy relationships.

\section{Acknowledgements}

This work was supported by the National Institutes of Health (R35 GM133470). M. L. K. was supported by the NSF Graduate Student Fellowship Grant No. DGE-1144082 and DGE-1746045. We thank the University of Chicago for funding as well as $3 \mathrm{M}$ corporation for a NTFA and the Sloan Foundation for a Research Fellowship to J.S.A. (FG-2019-11497). We also thank the Research Computing Center at the University of Chicago for providing computing resources. We thank Dr. Josh Kurutz for his helpful discussion and assistance with NMR spectroscopy and Joseph Schneider for helpful discussions.

Keywords: Electrostatics - Electric fields • Anionic phosphines • Hammett parameter $\cdot \mathrm{C}-\mathrm{F}$ borylation catalysis

[1] A. Warshel, J. Biol. Chem. 1998, 273, 27035-27038.

[2] A. Warshel, P. K. Sharma, M. Kato, Y. Xiang, H. Liu, M. H. M.
Olsson, Chem. Rev. 2006, 106, 3210-3235.

P. Schyman, W. Lai, H. Chen, Y. Wang, S. Shaik, J. Am. Chem. Soc. 2011, 133, 7977-7984.

S. D. Fried, S. G. Boxer, Acc. Chem. Res. 2015, 48, 998-1006.

[5] S. D. Fried, S. G. Boxer, Annu. Rev. Biochem. 2017, 86, 387-415.

[6] A. Morgenstern, M. Jaszai, M. E. Eberhart, A. N. Alexandrova, Chem. Sci. 2017, 8, 5010-5018.

[7] D. Bím, A. N. Alexandrova, ACS Catal. 2021, 11, 6534-6546.

[8] S. Shaik, D. Mandal, R. Ramanan, Nat. Chem. 2016, 8, 1091-1098.

[9] S. Shaik, R. Ramanan, D. Danovich, D. Mandal, Chem. Soc. Rev. 2018, 47, 5125-5145.

[10] S. Ciampi, N. Darwish, H. M. Aitken, I. Díez-Pérez, M. L. Coote, Chem. Soc. Rev. 2018, 47, 5146-5164.

[11] F. Che, J. T. Gray, S. Ha, N. Kruse, S. L. Scott, J.-S. McEwen, ACS Catal. 2018, 8, 5153-5174.

[12] S. Ye, C. Riplinger, A. Hansen, C. Krebs, J. M. Bollinger, F. Neese, Chem. - A Eur. J. 2012, 18, 6555-6567.

[13] M. Alemani, M. V Peters, S. Hecht, K. H. Rieder, F. Moresco, L. Grill, J. Am. Chem. Soc. 2006, 128, 14446-14447.

[14] C. F. Gorin, E. S. Beh, M. W. Kanan, J. Am. Chem. Soc. 2012, 134, 186-189.

[15] Y. Zang, Q. Zou, T. Fu, F. Ng, B. Fowler, J. Yang, H. Li, M. L. Steigerwald, C. Nuckolls, L. Venkataraman, Nat. Commun. 2019, 10, 1-7.

[16] C. F. Gorin, E. S. Beh, Q. M. Bui, G. R. Dick, M. W. Kanan, J. Am. Chem. Soc. 2013, 135, 11257-11265.

[17] A. C. Aragonès, N. L. Haworth, N. Darwish, S. Ciampi, N. J. Bloomfield, G. G. Wallace, I. Diez-Perez, M. L. Coote, Nature 2016 531, 88-91.

[18] M. Liu, Y. Pang, B. Zhang, P. De Luna, O. Voznyy, J. Xu, X. Zheng, C. T. Dinh, F. Fan, C. Cao, et al., Nature 2016, 537, 382-386.

[19] L. Zhang, E. Laborda, N. Darwish, B. B. Noble, J. H. Tyrell, S. Pluczyk, A. P. Le Brun, G. G. Wallace, J. Gonzalez, M. L. Coote, et al., J. Am. Chem. Soc. 2018, 140, 766-774.

[20] J. Ryu, Y. Surendranath, J. Am. Chem. Soc. 2019, 141, 1552415531.

[21] J. Heo, H. Ahn, J. Won, J. G. Son, H. K. Shon, T. G. Lee, S. W. Han, M.-H. Baik, Science 2020, 370, 214-219.

[22] M. Shetty, M. A. Ardagh, Y. Pang, O. A. Abdelrahman, P. J. Dauenhauer, ACS Catal. 2020, 10, 12867-12880.

[23] R. E. Warburton, P. Hutchison, M. N. Jackson, M. L. Pegis, Y. Surendranath, S. Hammes-Schiffer, J. Am. Chem. Soc. 2020, 142, 20855-20864.

[24] D. A. DiRocco, E. L. Noey, K. N. Houk, T. Rovis, Angew. Chem., Int. Ed. 2012, 51, 2391-2394.

[25] M. C. Holland, S. Paul, W. B. Schweizer, K. Bergander, C. MückLichtenfeld, S. Lakhdar, H. Mayr, R. Gilmour, Angew. Chem., Int. Ed. 2013, 52, 7967-7971.

[26] B. Chattopadhyay, J. E. Dannatt, I. L. Andujar-De Sanctis, K. A. Gore, R. E. Maleczka, D. A. Singleton, M. R. Smith III, J. Am. Chem. Soc. 2017, 139, 7864-7871. V. M. Lau, W. C. Pfalzgraff, T. E. Markland, M. W. Kanan, J. Am. Chem. Soc. 2017, 139, 4035-4041.

[28] T. Chantarojsiri, J. W. Ziller, J. Y. Yang, Chem. Sci. 2018, 9, 25672574.

[29] D. Dhar, G. M. Yee, W. B. Tolman, Inorg. Chem. 2018, 57, 97949806. 
K. Kang, J. Fuller, A. H. Reath, J. W. Ziller, A. N. Alexandrova, J. Y. Yang, Chem. Sci. 2019, 10, 10135-10142.

[31] J. D. Erickson, A. Z. Preston, J. C. Linehan, E. S. Wiedner, ACS Catal. 2020, 10, 7419-7423.

[32] A. C. Deacy, E. Moreby, A. Phanopoulos, C. K. Williams, j. Am. Chem. Soc. 2020, 142, 19150-19160.

[33] V. F. Oswald, J. L. Lee, S. Biswas, A. C. Weitz, K. Mittra, R. Fan, J. Li, J. Zhao, M. Y. Hu, E. E. Alp, et al., J. Am. Chem. Soc. 2020, 142, 11804-11817.

[34] D. J. Martin, S. I. Johnson, B. Q. Mercado, S. Raugei, J. M. Mayer, Inorg. Chem. 2020, 59, 17402-17414.

[35] A. B. Weberg, S. P. McCollom, L. M. Thierer, M. R. Gau, P. J. Carroll, N. C. Tomson, Chem. Sci. 2021, 12, 4395-4404.

[36] M. Klinska, L. M. Smith, G. Gryn'ova, M. G. Banwell, M. L. Coote, Chem. Sci. 2015, 6, 5623-5627.

[37] D. J. Martin, B. Q. Mercado, J. M. Mayer, Inorg. Chem. 2021, 60, 5240-5251.

[38] D. J. Martin, J. M. Mayer, J. Am. Chem. Soc. 2021, jacs.1c03132.

[39] K. Lee, D. L. Silverio, S. Torker, D. W. Robbins, F. Haeffner, F. W. van der Mei, A. H. Hoveyda, Nat. Chem. 2016, 8, 768-777.

[40] C. R. Kennedy, J. A. Guidera, E. N. Jacobsen, ACS Cent. Sci. 2016, 2, 416-423.

[41] G. Xiao, G. A. Cintron-Rosado, D. A. Glazier, B.-M. Xi, C. Liu, P. Liu, W. Tang, J. Am. Chem. Soc. 2017, 139, 4346-4349.

[42] S. Yamada, Chem. Rev. 2018, 118, 11353-11432.

[43] V. Dhayalan, S. C. Gadekar, Z. Alassad, A. Milo, Nat. Chem. 2019, 11, 543-551.

[44] J. Grajeda, M. R. Kita, L. C. Gregor, P. S. White, A. J. M. M. Miller, Organometallics 2016, 35, 306-316.

[45] A. H. Reath, J. W. Ziller, C. Tsay, A. J. Ryan, J. Y. Yang, Inorg. Chem. 2017, 56, 3713-3718.

[46] J. M. Um, D. A. Dirocco, E. L. Noey, T. Rovis, K. N. Houk, J. Am. Chem. Soc. 2011, 133, 11249-11254.

[47] E. Lyngvi, J. W. Bode, F. Schoenebeck, Chem. Sci. 2012, 3, 23462350.

[48] T. Stuyver, R. Ramanan, D. Mallick, S. Shaik, Angew. Chem., Int. Ed. 2020, 59, 7915-7920.

[49] L. Xu, E. I. Izgorodina, M. L. Coote, J. Am. Chem. Soc. 2020, 142, 12826-12833.

[50] V. Doan, B. B. Noble, M. L. Coote, J. Org. Chem. 2020, 85, 1009110097.

[51] V. V. Welborn, L. Ruiz Pestana, T. Head-Gordon, Nat. Catal. 2018, 1, 649-655.

[52] H. Yang, M. W. Wong, J. Am. Chem. Soc. 2013, 135, 5808-5818.

[53] Q. N. N. Nguyen, M. W. Lodewyk, S. Bezer, M. R. Gagné, M. L. Waters, D. J. Tantillo, ACS Catal. 2015, 5, 1617-1622.

[54] T. J. Seguin, S. E. Wheeler, ACS Catal. 2016, 6, 2681-2688.

[55] T. J. Seguin, S. E. Wheeler, Angew. Chem., Int. Ed. 2016, 55, 15889-15893.

[56] R. Maji, S. E. Wheeler, J. Am. Chem. Soc. 2017, 139, 1244112449.

[57] N. S. Hill, M. L. Coote, Aust. J. Chem. 2019, 72, 627-632.

[58] M. T. Blyth, M. L. Coote, J. Org. Chem. 2019, 84, 1517-1522.

[59] M. T. Blyth, B. B. Noble, I. C. Russell, M. L. Coote, J. Am. Chem. Soc. 2020, 142, 606-613.

[60] J. Joy, T. Stuyver, S. Shaik, J. Am. Chem. Soc. 2020, 142, 38363850.

C. Hansch, A. Leo, R. W. Taft, Chem. Rev. 1991, 91, 165-195. T. Ri, H. Eyring, J. Chem. Phys. 1940, 8, 433-443.

F. H. Westheimer, J. Am. Chem. Soc. 1939, 61, 1977-1980. H. H. Jaffé, J. Chem. Phys. 1952, 20, 279-284. H. H. Jaffé, Chem. Rev. 1953, 53, 191-261.

R. J. Burns, I. K. Mati, K. B. Muchowska, C. Adam, S. L. Cockroft, Angew. Chem., Int. Ed. 2020, 59, 2-10.

I. Azcarate, C. Costentin, M. Robert, J.-M. Savéant, J . Am. Chem. Soc. 2016, 138, 16639-16644.

M. L. Pegis, C. F. Wise, B. Koronkiewicz, J. M. Mayer, J. Am. Chem. Soc. 2017, 139, 11000-11003.

S. Sung, D. Kumar, M. Gil-Sepulcre, M. Nippe, J. Am. Chem. Soc. 2017, 139, 13993-13996.

Z. Yuan, H. Yang, N. Malik, M. Čolović, D. S. Weber, D. Wilson, F. Bénard, R. E. Martin, J. J. Warren, P. Schaffer, et al., ACS Catal. 2019, 9, 8276-8284.

S. Sung, X. Li, L. M. Wolf, J. R. Meeder, N. S. Bhuvanesh, K. A. Grice, J. A. Panetier, M. Nippe, J. Am. Chem. Soc. 2019, 141, 6569-6582.

R. Zhang, J. J. Warren, J. Am. Chem. Soc. 2020, 142, 1342613434.

C. G. Margarit, N. G. Asimow, M. I. Gonzalez, D. G. Nocera, J. Phys. Chem. Lett. 2020, 11, 1890-1895.

C. A. Tolman, Chem. Rev. 1977, 77, 313-348.

S. Qiao, D. A. Hoic, G. C. Fu, J. Am. Chem. Soc. 1996, 118, 63296330.

A. L. Chan, J. Estrada, C. E. Kefalidis, V. Lavallo, Organometallics 2016, 35, 3257-3260.

Y. Dai, S. He, B. Peng, L. A. Crandall, B. R. Schrage, C. J. Ziegler, L. Jia, Angew. Chem., Int. Ed. 2018, 57, 14111-14115.

P. J. Fischer, S. Senthil, J. T. Stephan, M. L. Swift, M. D. Storlie, E. T. Chan, M. V Vollmer, V. G. Young, Dalton Trans. 2018, 47, 61666176.

S. Konishi, T. Iwai, M. Sawamura, Organometallics 2018, 37, 18761883.

M. W. Drover, K. Nagata, J. C. Peters, Chem. Commun. 2018, 54, 7916-7919.

J. C. Thomas, J. C. Peters, J. Am. Chem. Soc. 2001, 123, 51005101. C. C. Lu, J. C. Peters, J. Am. Chem. Soc. 2002, 124, 5272-5273. J. C. Thomas, J. C. Peters, Inorg. Chem. 2003, 42, 5055-5073. A. L. Gott, W. E. Piers, J. L. Dutton, R. McDonald, M. Parvez, Organometallics 2011, 30, 4236-4249. Y. Kim, R. F. Jordan, Organometallics 2011, 30, 4250-4256.

S. L. Granville, G. C. Welch, D. W. Stephan, Inorg. Chem. 2012, 51 , 4711-4721.

M. Alcarazo, Acc. Chem. Res. 2016, 49, 1797-1805.

J. P. Tassone, R. C. Mawhinney, G. J. Spivak, J. Organomet. Chem. 2015, 776, 153-156.

9] R. A. Oliveira, R. O. Silva, G. A. Molander, P. H. Menezes, Magn. Reson. Chem. 2009, 47, 873-878.

L. Chen, P. Ren, B. P. Carrow, J. Am. Chem. Soc. 2016, 138, 6392-6395.

D. W. Allen, B. F. Taylor, J. Chem. Soc. Dalt. Trans. 1982, 51-54.

Z. L. Niemeyer, A. Milo, D. P. Hickey, M. S. Sigman, Nat. Chem. 2016, 8, 610-617. 
University Science, Herndon, VA, 2005.

[94] S. W. Carr, R. Colton, Aust. J. Chem. 1981, 34, 35-44.

[95] C. G. Hrib, F. Ruthe, E. Seppälä, M. Bätcher, C. Druckenbrodt, C. Wismach, P. G. Jones, W. W. du Mont, V. Lippolis, F. A.

Devillanova, et al., Eur. J. Inorg. Chem. 2006, 2006, 88-100.

[96] F. -W Grevels, J. Jacke, W. E. Klotzbücher, C. Krüger, K. Seevogel, Y. -H Tsay, Angew. Chem., Int. Ed. 1987, 26, 885-887.

[97] L. Cronin, C. L. Higgitt, R. Karch, R. N. Perutz, Organometallics 1997, 16, 4920-4928.

[98] X. W. Liu, J. Echavarren, C. Zarate, R. Martin, J. Am. Chem. Soc. 2015, 137, 12470-12473.

[99] T. Niwa, H. Ochiai, Y. Watanabe, T. Hosoya, J. Am. Chem. Soc. 2015, 137, 14313-14318.

[100] J. Zhou, M. W. Kuntze-Fechner, R. Bertermann, U. S. D. Paul, J. H. J. Berthel, A. Friedrich, Z. Du, T. B. Marder, U. Radius, J. Am. Chem. Soc. 2016, 138, 5250-5253.

[101] A. J. J. Lennox, G. C. Lloyd-Jones, Chem. Soc. Rev. 2014, 43, 412443. 


\section{Entry for the Table of Contents}

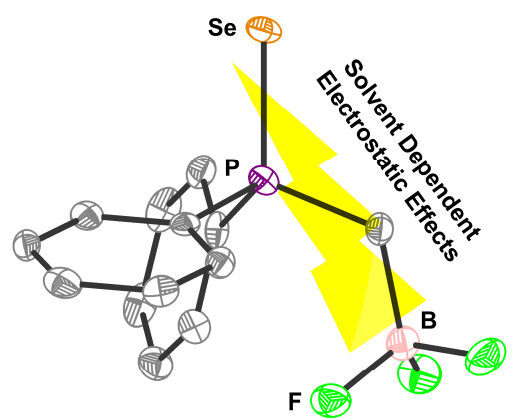

The relative inductive (through-bond) and electrostatic (through-space) contributions to donor strength in a novel anionic phosphine are quantified using phosphorus selenium coupling values in various solvents. These support that the enhanced donor strength in anionic phosphines is predominantly due to electrostatic contributions. Accelerated C-F oxidative addition by Ni complexes and rapid catalytic defluoroborylation is also demonstrated.

Institute and/or researcher Twitter usernames: @jsandersonlab 